\title{
Interventions To Reduce Sexual Violence In Pregnant Mothers: Systemic Review
}

\author{
Tetti Solehati ${ }^{1}$, Nadya Rahmanda ${ }^{2}$, Ratih Kusuma ${ }^{3}$, Aulia Rahmi $F^{4}$, Ryzka Fridelia $\mathrm{S}^{5}$, \\ Annisa Mifa Fitri E ${ }^{6}$, Nadilla Cynthia ${ }^{7}$, Cecep Eli Kosasih ${ }^{8}$, Yanti Hermayanti ${ }^{9}$, Hanny \\ Suzanna Mediani ${ }^{10}$ \\ \{*tetti.solehati@unpad.ac.id\}
}

Faculty of Nursing Universitas Padjdjaran

\begin{abstract}
Violence against women is a risk factor for poor health, resulting in the quality of women's health and well-being, including sections and improvements and poor mental health. Objective: Systematic review aimed to find out effective methods of reducing violence on intimate partners during pregnancy and after pregnancy. Method: Searching articles used electronic database i.e. Cinahl, Science Direct, Academic complete research, and PUBMED. Criteria for inclusion of articles taken included research articles from the last 10 years 2010-2020, randomized controlled trials or quasi experiments, English language, and full text. The search results found in the article by CINAHL according to keywords and based on the years 2010-2020 and full text as many as 11 articles, Science direct 6 articles, Academic complete research (EBSCO) 18 articles, and PUBMED 42 articles. After adjusting for inclusion criteria, there were 4 articles left, consisting of 2 articles from Science Direct database, 1 article from PUBMED and 1 article from Academic complete research. Results: There were several methods that can be used to reduce violence in intimate partners during pregnancy and after pregnancy there are 3 methods that can be used, including psycho-behaviour with the use of the VoorZorg program, Cognitive Behavioral Therapy, and non-professional mentor support. Conclusions: This study provides valid evidence of a method for reducing violence in intimate partners during pregnancy and after pregnancy. Further studies related to the prevention of violence in intimate partners can be done in more depth about the most effective measures to reduce intimate partner violence, as well as research in ASEAN.
\end{abstract}

Keywords: Pregnancy, Intimate Partner Violence, Domestic Violence

\section{Introduction}

Violence against women is a major public health problem with serious consequences for women's health [1]. Violence during pregnancy often involves a blow to the stomach, which may have serious consequences for both mother and baby [2]. Violence against women is associated with a variety of negative things [3], including death, injury, various mental and physical health problems, and adverse effects on sexual and reproductive health.

World Health Organization (WHO) report found that women who were physically and sexually abused by their partners reported higher health problems, like: $16 \%$ more likely to have low birth weight babies, having an abortion, almost prone to depression, and 1,5 times more likely to be infected with HIV compared to women who have not experienced partner 
violence [4], premature labor, low maternal weight gain, kidney infection, antepartum bleeding, cesarean birth, fetal miscarriage, and fetal death [5].

The prevalence of female violence by intimate partners is quite alarming. A Global Burden of Disease Study survey estimates a multi-country study (Bangladesh, Brazil, Ethiopia, Japan, Namibia, Peru, Samoa, Serbia, Thailand, America, and the Republic of Tanzania) found that the prevalence of an intimate partner physical violence was between $13 \%-61 \%$. Overall, between $15 \%$ and $71 \%$ of women report physical or sexual violence, or both during their lifetime [1]. In a multi-country study by the World Health Organization (WHO), the prevalence of physical abuse during pregnancy, among pregnant women, ranges from $4 \%$ to $12 \%$ on most sites [1].

This study aims to determine effective interventions in reducing violence in intimate partners during pregnancy and after pregnancy. This research is expected to benefit researchers, nurses, and other professions in gaining insight so that they can develop effective interventions for mothers who are victims of violence.

\section{Methodology}

\subsection{Search strategy}

Search based on PRISMA research protocol guidelines [6]. The preparation of a systematic review by searching for articles using an electronic database namely CINAHL, Sciencedirect, Academic complete research, and PubMed. Keywords used in English are "Pregnant Woman", "Domestic Violence", "Domestic Abuse", "Intimate Partner Violence", "Prevention Program", "Intervention Program", "Treatment Program". The article search results were found according to keywords as many as 297 and based on the years $2010-2020$ in the Cinahl database (EBSCO) as many as 14 articles, Sciencedirect 160 articles, Academic complete research (EBSCO) 47, and PubMed 76 articles.

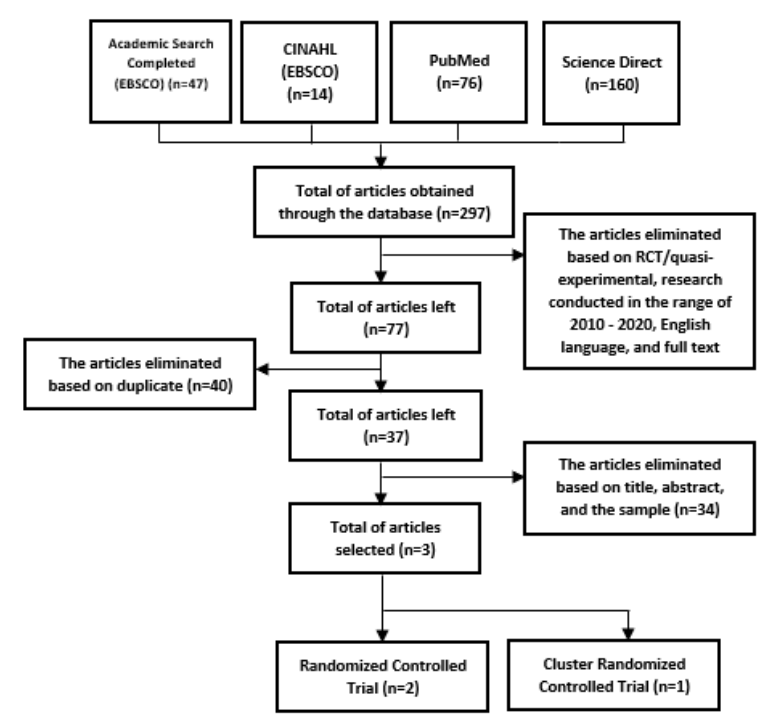

Fig.1. PRISMA Flow Diagram 


\subsection{Data extraction}

The articles obtained are adjusted to the inclusion criteria, namely quasi-experimental, full text, English language, research conducted in the range of $2010-2020$, in the form of intervention or prevention of violence in pregnant women. The sample size is chosen at least 30 in each group because this size is considered large enough to be able to assume that the variability of the intervention estimate can be estimated close by the normal distribution of the central boundary theorem [7]. Data extraction includes author, year of publication, outcome, study location, method, sample size, technic of sampling, intervention, result, and conclusion.

\section{Result and Discussion}

Five databases provide 297 articles. After applying the inclusion and exclusion criteria, 77 articles were left. Then a duplicate check is performed and the remaining 37 full tex articles remain for quality assessment. After a complete inspection, 3 articles remain. Analysis of the article focuses on prevention interventions that affect the reduction in the incidence of violence in pregnant women. (Picture 1). All the writer's team discusses the article if there is a discrepancy.

The article search process obtained three articles relating to interventions for domestic violence among pregnant women in the world. One of the three articles examined the effectiveness of psycho-behavioral interventions with the use of the VoorZorg program, one study tested the effectiveness of cognitive-behavioral therapy and another article about the effectiveness of non-professional mentor support.

\subsection{Psycho-Behavioral Interventions}

Studies conducted show that the VoorZorg program is effective in reducing the victimization and actions of Intimate Partner Violence (IPV) during pregnancy and two years after birth to pregnant women with low education. Furthermore, because this program serves to proactively minimize IPV, it may have long-term positive health effects on parents and their children [8]

A trusting relationship exists between the patient and the nurse through a home visit by the nurse. Factors that can increase the risk of IPV in general (for example, stress reduction), as well as factors that can increase the risk of IPV about certain people (for example, identifying abusive relationships), victimization, and actions due to IPV, are significantly lower during pregnancy and two years after birth can be overcome. This program works to proactively prevent IPV which may have long-term positive health effects on parents and their children [9]. VoorZorg is equivalent to Olds et al. who found that NFP had a positive and long-term effect on maternal and child development, but it was not found that NFP affected IPV during pregnancy and after birth [10]. With the Mejdoubi et al article that gets new findings of the positive effect, the program has on IPV action among young pregnant women [8]. Some researchers believe that many participants are reluctant to report violence in family because nurses in the United States are required to report child abuse and participants who may be at risk of losing their child to the Child Protection Service [11]. VoorZorg nurses are considered to be able to handle IPV more effectively because it can reduce violence in pregnant women and children. Mejdoubi et al. revealed that home visits reduced the incidence of intimate 
partner violence in a sample of high-risk young pregnant women [8]; Future analysis will reveal whether additional impacts on child abuse and neglect will be found that must be in line with the findings of Eckenrode et al. which shows that the presence of IPV moderates the impact of the program on preventing child abuse and neglect [12].

Mejdoubi et al. found that a high level of psychological aggression at 24 months, this highrisk sample of low-educated young pregnant women, $100 \%$ reported experiencing psychological violence, 58\% reported experiencing physical violence, $26 \%$ reported experiencing injury after a fight and 16\% experienced sexual violence during pregnancy [8]. All women in this sample experienced psychological violence, which suggests that it might be situational partner violence that might be present in many all couples [13]. Mc Farlane et al. report that $17 \%$ of low income, pregnant women experience physical or sexual violence [14]. This finding emphasizes the importance of health workers to focus on this vulnerable group. It is important to break this cycle of violence.

\subsection{Cognitive Behavior Therapy}

This intervention provides information on the types of abuse (e.g, emotional, physical and sexual) and the cycle of violence (e.g, increase, IPV, honeymoon period), Hazard Assessment Components to assess risk, and prevention options that women might consider (e.g, filing protective orders) and developing a safety plan (e.g, leaving important documents and papers with others). As a result, relatively brief counseling interventions during pregnancy have a visible but not significant effect [15].

Research conducted by [15] conducting cognitive behavioral therapy based on structured interventions developed by Parker and colleagues and based on the Dutton Empowerment Theory [16] results such as women with severe IPV experience can increase future IPV and women who have given the intervention of having fewer preterm infants $(p=0.03)$ and increasing mean gestational age $(\mathrm{p}=0.016)$. There is a significant relationship between IPV and the use of illegal drugs $(16.7 \%)$ and active smoking $(22 \%)$, entirely associated with risk for PTB and LBW [17,18]. These are risk factors which can be quite severe and lasting problems

IPV has been approved for pregnancy complications (for example, inadequate weight gain, infection, and bleeding) as well as adverse pregnancy outcomes (LBW), premature birth (PTB), and neonatal death [19][20]. Kiely et al. Find women who successfully overcome intimate partners who are depressed and anxious, women who are smoking, drinking alcohol, and drugs [21]. This can affect medical conditions that might worsen pregnancy and fetal conditions. The American College of Obstetricians and Gynecologists respond to responses to domestic defenses against women as a priority and oppose screening in primary care settings [22]. Cognitive-behavioral therapy is the basic foundation for applying cognitive principles. Cognitive-effective therapy can reduce the level of hyperactivity, impulsivity, and aggression [23]. ognitive-enhancing cognitive therapy in adolescents, demonstrating the success of cognitive-cognitive interventions in improving social intelligence and cognitive self-control, rehabilitation management and alternative thinking that reduces mental protection parameters in the experimental group [24]

\subsection{Non-professional Mentor Support}

In the intervention of the Advocate Mother in the Community (MOSAIC) conducted by Taft et al (2011) consisting of 90 intervention groups and 43 comparison groups, using the mentoring method carried out for 12 months which was made into 4 mentoring sessions namely 1 month, 4 months, 8 months and 12 months. The mentoring activity was only given 
to the intervention group participants of 90 people. After the mentoring activity was completed, in the 12th month, the mentor followed up the outcome measures by giving questionnaires to all participants to decide the current status of all the main outcome measures; general health, depression, IPV, relationship status, parental pressure, use of health services and satisfaction, social support. Non-professional mentor support has the effect of increasing safety and increasing physical and mental well-being among mothers who experience postviolence. The results showed that the rate of depression in depressed women who experienced violence was lower after being given intervention with support from a mentor compared to a control group without mentor support. This is indicated by the results in the intervention group that produces a value of stress reduction $(p=0.08)$. Non-professional mentor support for 12 months has the effect of increasing safety and increasing physical and mental well-being among mothers who experience violence from their partners [11]. The same thing was also found from [25] which showed that women who received support in the form of cognitive learning were proven to reduce depression and women from intimate partner difficulties. This can be used to increase defenses in the household and to improve the health of victims.

Interventions conducted [26] show that individual counseling with mentors, telephone support, and a booklet giving can reduce the anxiety they feel because they feel the experience they feel can be shared and listened to. Just like the research conducted [27] that women who receive support by being given education in terms of psychology and emotions for the first time feel more confident and reduce guilt for events in the past. This is in line with research [28] which conducted a support group system with women with violence experienced a decrease in anxiety and better mental health.

\section{Conclusion}

This study provides valid evidence of a method for reducing violence in intimate partners during pregnancy and after pregnancy. Further studies related to the prevention of violence in intimate partners can be done in more depth about the most effective measures to reduce intimate partner violence, as well as research in ASEAN.

\section{References}

[1] Garcia-Moreno C, Stöckl H. Violence against Women. Int. Encycl. Public Heal., 2016. https://doi.org/10.1016/B978-0-12-803678-5.00483-5.

[2] Stöckl H, Gardner F. Women's perceptions of how pregnancy influences the context of intimate partner violence in Germany. Cult Heal Sex 2013. https://doi.org/10.1080/13691058.2013.813969.

[3] Campbell JC. Health consequences of intimate partner violence. Lancet 2002. https://doi.org/10.1016/S0140-6736(02)08336-8.

[4] WHO D of RHRLS of H and TMSAMRC. WHO | Global and regional estimates of violence against women. WHO 2013.

[5] Cokkinides VE, Coker ANNL, Sanderson M, Addy C, Bethea L. Physical Violence During Pregnancy : Maternal Complications and Birth Outcomes 1999;93:661-6.

[6] Moher D, Liberati A, Tetzlaff J, Altman DG, Altman D, Antes G, et al. Preferred reporting items for systematic reviews and meta-analyses: The PRISMA statement. PLoS Med 2009. https://doi.org/10.1371/journal.pmed.1000097.

[7] Hutchins SS. Value of a small control group for estimating intervention effectiveness : results from simulations of immunization effectiveness studies 2015;4:227-38. 
[8] Mejdoubi J, van den Heijkant SCCM, van Leerdam FJM, Heymans MW, Hirasing RA, Crijnen AAM. Effect of Nurse Home Visits vs. Usual Care on Reducing Intimate Partner Violence in Young High-Risk Pregnant Women: A Randomized Controlled Trial. PLoS One 2013;8:1.

[9] Dutton DG. The Prevention of Intimate Partner Violence. Prev Sci 2012;13:395-7. https://doi.org/10.1007/s11121-012-0306-1.

[10] Olds DL, Kitzman H, Cole R, Robinson J, Sidora K, Luckey DW, et al. Effects of Nurse HomeVisiting on Maternal Life Course and Child Development: Age 6 Follow-Up Results of a Randomized Trial. Pediatrics 2004;114:1550 LP - 1559. https://doi.org/10.1542/peds.2004-0962.

[11] Taft AJ, Small R, Hegarty KL, Watson LF, Gold L, Lumley JA. Mothers' AdvocateS in the Community (MOSAIC)-non-professional mentor support to reduce intimate partner violence and depression in mothers: A cluster randomised trial in primary care. BMC Public Health 2011;11:178. https://doi.org/10.1186/1471-2458-11-178.

[12] Eckenrode J, Ganzel B, Henderson Charles R. J, Smith E, Olds DL, Powers J, et al. Preventing Child Abuse and Neglect With a Program of Nurse Home VisitationThe Limiting Effects of Domestic Violence. JAMA 2000;284:1385-91. https://doi.org/10.1001/jama.284.11.1385.

[13] Johnson MP, Leone JM. The Differential Effects of Intimate Terrorism and Situational Couple Violence: Findings From the National Violence Against Women Survey. J Fam Issues 2005;26:322-49. https://doi.org/10.1177/0192513X04270345.

[14] McFarlane J, Parker B, Soeken K, Bullock L. Assessing for Abuse During Pregnancy: Severity and Frequency of Injuries and Associated Entry Into Prenatal Care. JAMA 1992;267:3176-8. https://doi.org/10.1001/jama.1992.03480230068030.

[15] Kiely M, El-mohandes AAE, El-khorazaty MN, Gantz MG. An integrated intervention to reduce intimate partner violence in pregnancy: A randomized controlled trial 2011;115:273-83. https://doi.org/10.1097/AOG.0b013e3181 cbd482.AN.

[16] Parker B, McFarlane J, Soeken K, Silva C, Reel S. Testing an intervention to prevent further abuse to pregnant women. Res Nurs Heal 1999. https://doi.org/10.1002/(SICI)1098240X(199902)22:1<59::AID-NUR7>3.0.CO;2-B.

[17] Paranjape A, Heron S, Thompson M, Bethea K, Wallace T, Kaslow N. Are alcohol problems linked with an increase in depressive symptoms in abused, inner-city African American women? Women's Heal Issues 2007;17:37-43. https://doi.org/10.1016/j.whi.2006.08.004.

[18] Cnattingius S. The epidemiology of smoking during pregnancy: Smoking prevalence, maternal characteristics, and pregnancy outcomes. Nicotine Tob Res 2004;6:S125-40. https://doi.org/10.1080/14622200410001669187.

[19] Yost NP, Bloom SL, McIntire DD, Leveno KJ. A prospective observational study of domestic $\begin{array}{lllll}\text { violence } & \text { during } & \text { Obstet } & \end{array}$ https://doi.org/10.1097/01.AOG.0000164468.06070.2a.

[20] Janssen PA, Holt VL, Sugg NK, Emanuel I, Critchlow CM, Henderson AD. Intimate partner violence and adverse pregnancy outcomes: A population-based study. Am J Obstet Gynecol 2003. https://doi.org/10.1067/mob.2003.274.

[21] Kiely M, El-Mohandes AAE, El-Khorazaty MN, Gantz MG. An integrated intervention to reduce intimate partner violence in pregnancy: A randomized controlled trial. Obstet Gynecol 2010;115:273-83. https://doi.org/10.1097/AOG.0b013e3181cbd482.

[22] Durant T, Colley Gilbert B, Saltzman LE, Johnson CH. Opportunities for intervention: Discussing physical abuse during prenatal care visits. Am J Prev Med 2000. https://doi.org/10.1016/S0749-3797(00)00232-4.

[23] Robinson TR, Smith SW, Miller MD, Brownell MT. Cognitive Behavior Modification of Hyperactivity-Impulsivity and Aggression: A Meta-Analysis of School-Based Studies 1999. https://doi.org/10.1037/0022-0663.91.2.195.

[24] Qutaiba A. Cognitive behavioral intervention in dealing with school violence among Arab Palestinian adolescents in Israel 2010;5:1317-25. https://doi.org/10.1016/j.sbspro.2010.07.282.

[25] Latif M, Khanam SJ. Effectiveness of cognitive behaviour therapy in reducing anxiety, depression and violence in women affected by intimate partner violence: A randomized controlled trial from a low-income country. J Postgrad Med Inst 2017. 
[26] Sapkota Di, Baird K, Saito A, Rijal P, Pokharel R, Anderson D. Counselling-based psychosocial intervention to improve the mental health of abused pregnant women: A protocol for randomised controlled feasibility trial in a tertiary hospital in eastern Nepal. BMJ Open 2019;9:1-10. https://doi.org/10.1136/bmjopen-2018-027436.

[27] Evans M, Malpass A, Agnew-Davies R, Feder G. Women's experiences of a randomised controlled trial of a specialist psychological advocacy intervention following domestic violence: A nested qualitative study. PLoS One 2018. https://doi.org/10.1371/journal.pone.0193077.

[28] Ferrari G, Feder G, Agnew-Davies R, Bailey JE, Hollinghurst S, Howard L, et al. Psychological advocacy towards healing (PATH): A randomized controlled trial of a psychological intervention in a domestic violence service setting. PLoS One 2018. https://doi.org/10.1371/journal.pone.0205485.

[29] Rakhshani A, Nagarathna R, Mhaskar R, Mhaskar A, Thomas A, Gunasheela S. The effects of yoga in prevention of pregnancy complications in high-risk pregnancies: a randomized controlled trial. Prev Med (Baltim) 2012;55:333-40. https://doi.org/10.1016/j.ypmed.2012.07.020. 
Tab1e. Interventions to Reduce Sexual Violence in Pregnant Mothers

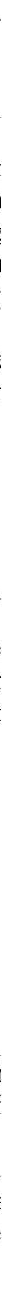

